\title{
Dubin Johnson Syndrome associated with defective ristocetin - induced platelet agglutination
}

\begin{abstract}
Background: This is the first reported case of platelet aggregation defect in association with Dubin-Johnson Syndrome.

Case presentation: We reported a 14 months old female infant with recurrent attacks of mild to moderate ear and nose bleeding and moderate amount of subarachnoid hemorrhage with ristocetin induced platelet agglutination other than Von Willebrand Factor disease and Bernard-Soulier syndrome. The patient also had fluctuating bilirubin level (Maximum of $15 \mathrm{mg} / \mathrm{dl}$ ) and remaining liver function tests were normal; the patient diagnosed as Dubin Johnson Syndrome by liver biopsy.
\end{abstract}

Conclusions: Dubin-Johnson Syndrome may be associated with platelet aggregation defect.

Keywords: Dubin-Johnson Syndrome, platelet aggregation defect
Volume 9 Issue 5 - 202 I

\author{
Samar Mohamad Elfiky, Shaimaa Ismail \\ Sahmoud \\ Department of Pediatric Hematology, Faculty of medicine, Suez \\ Canal University, Egypt
}

Correspondence: Samar Mohamad Elfiky, MD, Lecturer of Pediatrics, Faculty of Medicine, Suez Canal University, Ismailia, Egypt, Tel +20I I I8163880,Email dr_samar.elfiky@yahoo.com

Received: August 09, 2021 | Published: September 29, 2021
Abbreviations: DJS, dubin johnson syndrome; ITP, immune thrombocytopenic purpura

\section{Introduction}

Dubin-Johnson syndrome (DJS); is an autosomal recessive disorder characterized by chronic mild conjugated hyperbilirubinemia, without other features of hepatobiliary disease (OMIM*237500). ${ }^{1}$ It was found that DJS results from mutations in the protein encoded by the gene $\mathrm{ABCC} 2$ that helps in the transport of organic anions into the bile canaliculi. ${ }^{2,3}$ The decreased canalicular and increased intracellular ABCC2; decreases the bile secretion thus cause cholestasis. ${ }^{4}$ DJS was reported in association with some causes of bleeding tendency as factor VII deficiency, ${ }^{5,6}$ immune thrombocytopenic purpura (ITP). Other case reports found an association between DJS and systemic lupus erythematosus, and hepatic cavernous hemangioma. ${ }^{8,9}$ To the best of our knowledge, no DJS cases were reported in association with platelet aggregation defect.

\section{Case presentation}

Our 8 month female patient was the $5^{\text {th }}$ in order for a positive consanguineous parents (cousins), her pregnancy passed uneventful and delivered by normal vaginal delivery at term without complication, the immediate postnatal period also was free from any complications or drug intake. At the age of 15 days, she developed multiple ecchymotic patches all over the body, pallor, and depressed activity. At this time initial bleeding screening revealed normal platelet count 250.000, PT, and PTT. However, her hemoglobin $(\mathrm{Hb})$ was $10 \mathrm{gm} \%$ and CT brain showed moderate subarachnoid hemorrhage. Despite of the normal coagulation profile she received intramuscular vitamin $\mathrm{K}$ and fresh frozen plasma transfusion and 4 days later, she regained her full activity and was discharged.

At the age of 45 days, she presented to our hematology clinic with history of 4 to 5 attacks of epistaxis and external ear bleeding since NICU discharge. Complete blood count $(\mathrm{CBC})(\mathrm{HB}=11 \mathrm{gm} / \mathrm{dl}$, $\mathrm{Plt}=$
$285000 \mathrm{c} / \mathrm{cmm}, \mathrm{TLC}=10.500 \mathrm{c} / \mathrm{cmm}) ; \mathrm{PT}=13 \mathrm{sec}($ control is 13$)$, $\mathrm{APTT}=35 \mathrm{sec}$ (control is $37 \mathrm{sec}$ ) were normal; but bleeding time was more than 10 minutes. Accordingly Von Willberand Factor (VWF) antigen and ristocetin cofactor activity and platelet aggregation tests were done. Von Willberand Factor antigen and activity were normal $(160 \%$, and $113 \%)$, platelet function tests showed decreased aggregation response to ristocetin 33\% (normal $=70-120 \%$ ) with slight reduction on aggregation response to collagen $60 \%$ (normal= $70-120 \%$ ), and normal aggregation response to ADP $105 \%$ (normal= 70-120\%). Bernard-Soulier syndrome was suspected but glycoprotein (Gp) Ib/IX/V was normally expressed. Bleeding transiently stopped after platelet transfusion and the infant was discharged for follow up.

At the age of 5 months, she was still having recurrent mild to mod attacks of bleeding that stops with platelet transfusion. However she presented with new complain of jaundice and clay stool. Clinical examination at that time revealed mild jaundice, no pallor, no ecchymotic patches, no hepatomegaly or splenomegaly. $\mathrm{CBC}$ values were as follows: $\mathrm{HB}=9 \mathrm{gm} \%, \mathrm{TLC}=7000 \mathrm{c} / \mathrm{cmm}, \mathrm{PLT}=400.000 \mathrm{c} /$ $\mathrm{cmm}$; total bilirubin was $9.4 \mathrm{mg} / \mathrm{dl}$ with $8.1 \mathrm{mg} / \mathrm{dl}$ direct bilirubin; liver enzymes were normal ; ALT $=24 \mathrm{U} / \mathrm{L}, \mathrm{AST}=34 \mathrm{U} / \mathrm{L}, \mathrm{GGT}=28$ $\mathrm{U} / \mathrm{L}$ (normal $=(5-85)$, Alkaline phosphatase $=316 \mathrm{U} / \mathrm{L}$ normal $(4-140$ ), serum albumin $=3.8 \mathrm{gm} / \mathrm{L}, \mathrm{PT}=11 \mathrm{sec}, \mathrm{PTT}=30 \mathrm{sec}$, serology for hepatitis $\mathrm{A}, \mathrm{B}$ and $\mathrm{C}$ antibodies were negative, and TORCH screen showed positive Toxoplasma IgG, while rubella and cytomegalovirus immunoglobulin were negative. Abdominal ultrasonography was also normal. However, one week later serum bilirubin levels declined to $3.2 \mathrm{mg} / \mathrm{dl}$ total and $2.7 \mathrm{mg} / \mathrm{dl}$ direct bilirubin and stabilized at almost the same values for almost two months before direct bilirubin surged to $13.8 \mathrm{gm} / \mathrm{dl}$ with normal liver function. Abdominal ultrasonography had been repeated and again showed normal liver size and texture with no signs of intrahepatice biliary atresia so Tc99m IDA hepatobiliary scintigraphy was done and it ruled out extrahepatic biliary atresia with only delayed hepatic to bowel tracer transit (Figure 1). Urinary Coproporphyrins were not available, and liver biopsy was planned. 


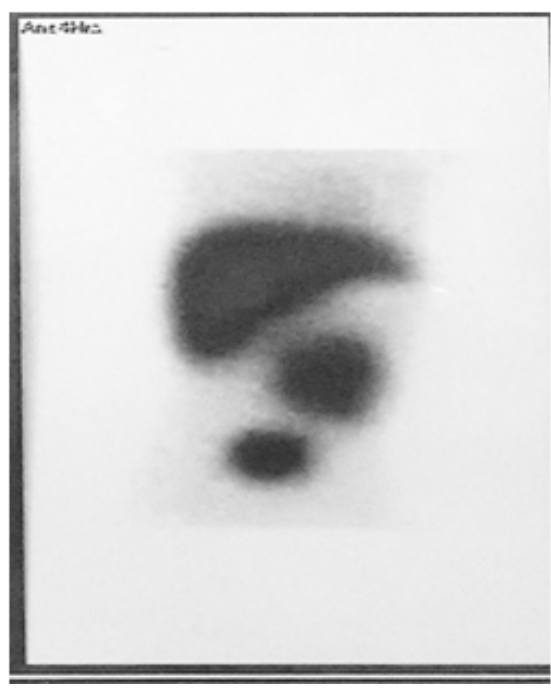

(A)

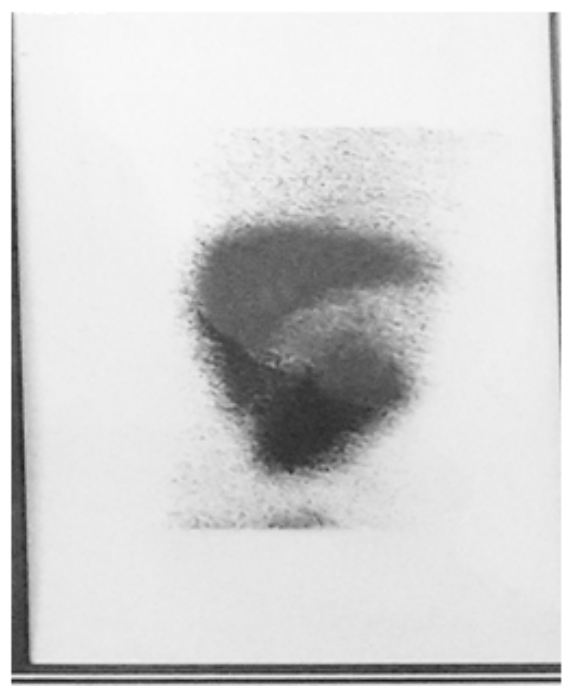

(B)

Figure I Tc ${ }^{99} \mathrm{~m}$ IDA Hepato-Biliary Scintigraphy

(A) The tracer appeared in the bowel in 5 hours image. (B) the tracer filled the bowel lobes in the 24 hours image.

Before liver biopsy platelet functions tests was repeated revealing normal platelet aggregation in response to $\operatorname{ADP}(81 \%)$ and a muchreduced response to ristocetin $(10 \%)$. Liver biopsy procedure passed with no bleeding as the infant received platelet transfusion before. The histopathology examination depict that liver cells were free from any

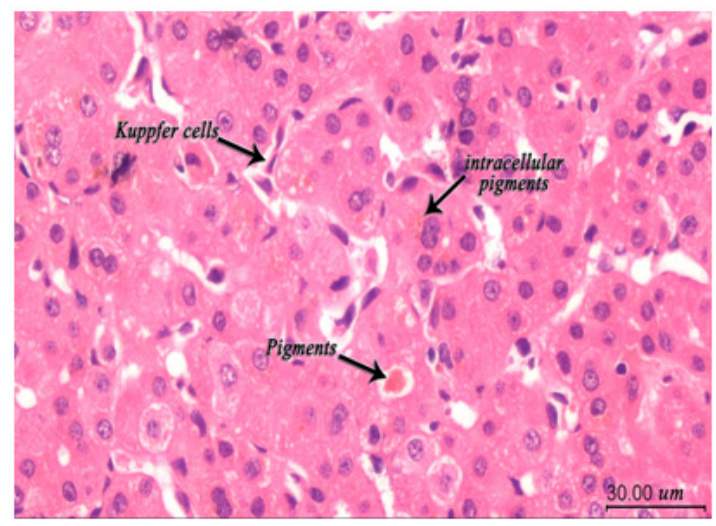

(A) necrotic or inflammatory lesions but there was microvascular steatosis and coarse brown black pigment in the perivenular liver cells with Kupffer cells hyperplasia suggesting the diagnosis of Dubin-Johnson Syndrome (Figure 2). ${ }^{7-9}$

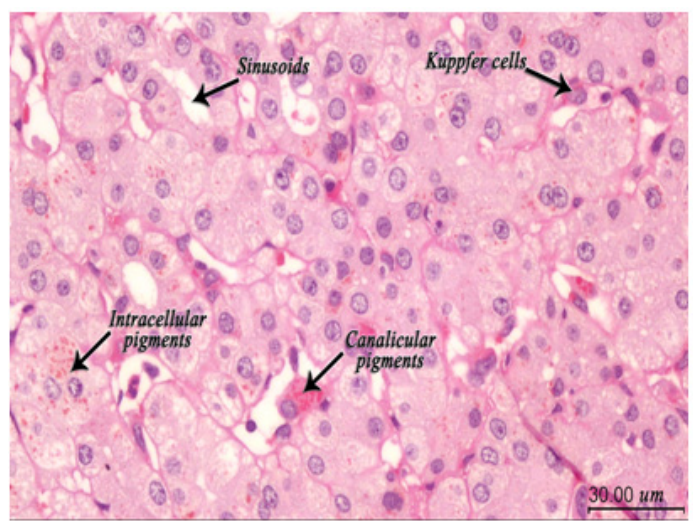

(B)

Figure 2 Liver biopsy.

(A) H\&E examination at 400x magnification. Liver tissue with preserved architecture, hyperplasia of Kuppfer cells, accumulation of pigment inclusions both intracellular and cancalicular. (B) PAS stains at 400x magnification. Highlights the pigments even with few foci. All Images captured using: Calibrated standard digital microscope camera (ToupTek ${ }^{\circledR}$ XCAMI080PHA digital microscope camera) using Olympus ${ }^{\circledR}$ CX2I microscope, with resolution of 5 MP (megapixels) 1920 x 1080 pixel. "ToupView” software for capture and image enhancements.

\section{Discussion}

The physiological role of platelets is to help hemostasis at sites of vascular injury through formation of platelet plugs that adhere to the exposed subendothelial collagen and to collagen-immobilized von Willebrand factor (VWF). Platelet adhesion initiates activation events that spread to increase surface contact. ${ }^{10}$ The prevalence of inherited platelet disorders is unknown. A survey of pediatric centers in Germany, Austria, and Switzerland estimated two affected children per million populations. ${ }^{11}$ Mild platelet function disorders (PFDs) are complex and difficult to diagnose, most affected individuals have mucocutaneous bleeding including bruising, epistaxis, bleeding from oropharynx or gastrointestinal tract. ${ }^{12}$ Bernard-Soulier syndrome (BBS) BBS is an autosomal recessive disorder (OMIM*231200), its diagnostic criteria of BSS are giant platelets, defective ristocetininduced platelet agglutination, a lack of VWF dependent platelet adhesion to subendothelium..$^{13}$ Platelet counts in BSS mostly range from $40000 / \mathrm{L}$ to near normal. ${ }^{14} \mathrm{BBS}$ is the product of four distinct genes (Iba, Ibb, IX andV). The genes for GPIba and GPIbb are on chromosomes 17 and 22, while those encoding GPIX and GPV are 
on chromosome 3. The GPIba gene is most frequently affected in BSS. ${ }^{15}$ In our case we found a defective ristocetin-induced platelet agglutination but with normal platelet morphology and count beside a normal GP 1b- IX complex. We faced the limitation of the inability to do gene mapping for BBS. Noticeably all the bleeding attacks in our infant was completely controlled by platelet transfusion. The fore-mentioned work up of the direct hyperbilirubinemia in our infant reached the diagnosis of Dubin Johnson syndrome and we found no previous reported cases of the same association thus a concurrent association is suggested.

\section{Conclusion}

This is the first reported familial case of DJS with platelet aggregation defect.

\section{Acknowledgments}

We would like to thank our colleagues from the biochemistry, immunology, histopathology laboratory departments as well as the intervention radiology arm in taking the liver biopsy.

\section{Conflicts of interest}

The authors declare no conflicts of interest.

\section{References}

1. Erlinger S, Arias IM, Dhumeaux D. Inherited disorders of bilirubin transport and conjugation: new insights into molecular mechanisms and consequences. Gastroenterology. 2014;146(7):1625-1638.

2. Kajihara S, Hisatomi A, Mizuta T, et al. A splice mutation in the human canalicular multispecific organic anion transporter gene causes Dubin-Johnson syndrome. Biochemical and biophysical research communications. 1998;253(2):454-457.

3. Keppler D. Multidrug resistance proteins (MRPs, ABCCs): importance for pathophysiology and drug therapy. Handb Exp Pharmacol. 2011;(201):299-323.

4. Kast HR, Goodwin B, Tarr PT, et al. Regulation of multidrug resistanceassociated protein 2 (ABCC2) by the nuclear receptors pregnane $\mathrm{X}$ receptor, farnesoid $\mathrm{X}$-activated receptor, and constitutive androstane receptor. Journal of Biological Chemistry. 2002;277(4):2908-2915.
5. Seligsohn U, Shani M, Ramot B, et al. Dubin-Johnson Syndrome In Israel: II. Association with Factor-VII Deficiency1. QJM: An International Journal of Medicine. 1970;39(4):569-584.

6. Mor-Cohen R, Zivelin A, Fromovich-Amit, et al. Age estimates of ancestral mutations causing factor VII deficiency and Dubin-Johnson syndrome in Iranian and Moroccan Jews are consistent with ancient Jewish migrations. Blood coagulation \& fibrinolysis. 2007;18(2):139144.

7. Du JN, Stauffer MH, Levin M, et al. Dubin-Johnson syndrome and idiopathic thrombocytopenic purpura in one patient. Canadian Medical Association Journal. 1965;92(15):839.

8. Mahtab MA, Karim MF, Rahman S, et al. Dubin-Johnson syndrome with systemic lupus erythematosus: a case report. Hepatobiliary Pancreat Dis Int. 2006;5(4):617-619.

9. Li P, Wang Y, Zhang J, et al. Dubin-Johnson syndrome with multiple liver cavernous hemangiomas: report of a familial case. International journal of clinical and experimental pathology. 2013;6(11):2636.

10. Nurden P, Nurden AT. Congenital disorders associated with platelet dysfunction. Thrombosis and Haemostasis-Stuttgart. 2008; 99(2):253.

11. Knöfler R, Streif W. Strategies in clinical and laboratory diagnosis of inherited platelet function disorders in children. Transfusion Medicine and Hemotherapy. 2010;37(5):231-235.

12. Cattaneo M. Light transmission aggregometry and ATP release for the diagnostic assessment of platelet function. In Seminars in thrombosis and hemostasis. 2009;35(2):158.

13. Nurden AT, George JN. Inherited abnormalities of the platelet membrane: Glanzmann thrombasthenia, Bernard-Soulier syndrome, and other disorders. In: Colman RW, Marder VJ, Clowes AW, George JN, Goldhaber SZ eds. Hemostasis and Thrombosis. Basic Principles and Clinical Practice. Vth Edition. Philadelphia: Lippincott, Williams \& Wilkins, 2005.

14. Geddis AE, Kaushansky K. Inherited thrombocytopenias: toward a molecular understanding of disorders of platelet production. Current opinion in pediatrics. 2004;16(1):15-22.

15. López JA, Andrews RK, Afshar-Kharghan V, et al. Bernard-soulier syndrome. Blood. 1998;91(12):4397-4418. 